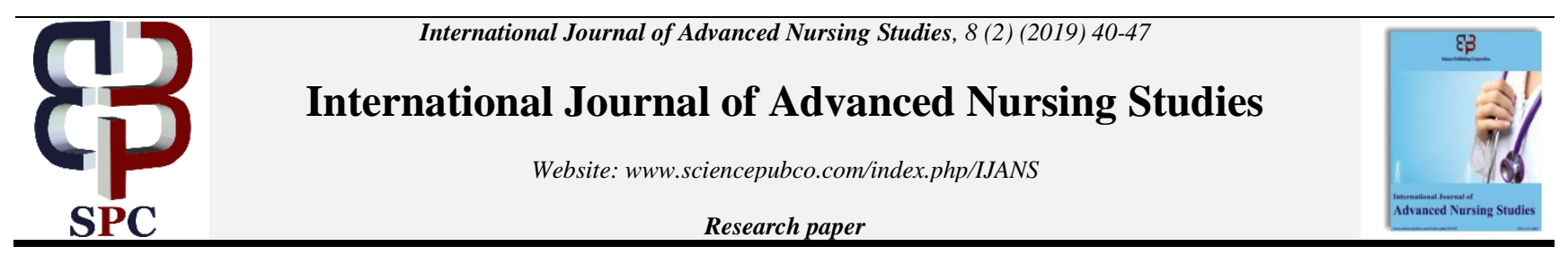

\title{
Registered nurses' attitude and willingness to precept nursing students in Jamaica
}

\author{
Michelle Roper Carty MSN ${ }^{1}$, Jascinth LM Lindo PhD ${ }^{1,2 *}$, Rosain Stennett MPH ${ }^{1}$ \\ ${ }^{1}$ The UWI School of Nursing, The University of the West Indies 9 Gibraltar Camp Way Mona, Kingston 7, Jamaica \\ ${ }^{2}$ University of Central Florida 12201 Research Parkway Orlando Florida 32826 \\ *Corresponding author E-mail: jaslindo@hotmail.com
}

\begin{abstract}
Background: Registered nurses' willingness to precept nursing students is an important factor in ensuring a positive clinical learning environment. However, in resource poor settings with high patient to nurse ratio and other challenges in the delivery of nursing care preceptorship may represent an additional challenge.

Aim: To determine the willingness of registered nurses to precept student nurses in Jamaica; their attitude towards the paired preceptorship model and factors which may influence the precepting process.

Design: This descriptive cross-sectional study utilized a 32 -item self-administered questionnaire to collect data from 76 full-time registered nurses assigned to medical/surgical wards at a major teaching hospital.

Results: Nurses had a positive attitude towards precepting $(97 \%)$ and believed their actions and attitudes positively influenced the learning outcomes of students. Two-thirds of registered nurses (63\%) were willing to precept students and $87 \%$ preferred the paired preceptorship model. Self-efficacy $(\mathrm{p}<0.05)$ best explained their willingness to participate in both paired preceptorship and clinical teaching associate models while, normative beliefs regarding clinical learning environment was significant predictor of overall willingness.

Conclusion: Registered nurses studied displayed positive attitude towards preceptorship and were willing to precept students. Policy makers should note that the paired preceptorship model was favoured by the group and that personal satisfaction and professional development were motivating factors for nurses' willingness to precept students. Formal training opportunities are needed to enhance students' clinical learning experience.
\end{abstract}

Keywords: Precept; Willingness; Registered Nurses; Student Nurses; Jamaica.

\section{Introduction}

Preceptorship is an important aspect of the clinical training of nursing students, as it facilitates their ability to incorporate theory into practice and prepares them for clinical work (Andreas 2016; Cooper et al. 2011; Duteau 2012; Happell 2009; Smedley 2008). Through preceptorship, students gain the ability to apply concepts learnt. This process is facilitated by a preceptor [a nurse who provides a learning environment, in which he or she teaches, coaches, supports, counsels and evaluates the clinical experience of a student nurse] (Anderas 2016; Carlson et al. 2010; McClure \& Black 2013; Smoker 2018). As the registered nurse fulfils the role of preceptor, professional development and clinical educational needs of the student are met (Bott et al. 2011; Evans 2013; L'Ecuyer 2019).

Nurse preceptors are required to possess characteristics in keeping with their role including having good communication skills, the ability to stimulate critical thinking and a positive attitude towards teaching and learning (Barker \& Pittman 2010; Duteau 2012; Schuelke \& Barnason 2017). The registered nurse should be a good role model; a key element to nurturing the students' desires for professional knowledge and development (Evans et al. 2013; Myrick et al. 2010; Schuelke \& Barnason 2017). Rebholz and Baumgartner (2015), highlighted the need for additional research on the role of emotion in the preceptor/preceptee relationship and the teaching/learning transactions. The lack of formal training, technical competence and limited knowledge to facilitate students' learning and professional development are challenges which many nurses face when asked to precept student nurses (Omer et al. 2016; Parker et al. 2012; Shinners, Mallory, \& Franqueiro 2013; Smoker 2018). Failure to prepare registered nurses for the preceptorship role may adversely affect their ability to become effective teachers and role models (Christine et al. 2000). There are significant benefits to be gained by training nurse preceptors as the preceptor role provides registered nurses with the opportunity to enhance their professional development, improve self- esteem, knowledge and clinical skills (Liu et al 2019; James \& Chapman 2010; Shinners et al. 2013). Moreover, students at the undergraduate level are more likely to have a positive learning experience, demonstrate greater levels of competency in their practice with clinical guidance and role modelling from an experienced staff nurse who has been trained as a preceptor (Harrison-White \& Simons 2013; McClure \& Black 2013; McSharry \& Lathlean 2017).

The preceptorship experience involves three players, the preceptor, the preceptee and the faculty member (Sedgwick \& Harris 2012). Each member has a critical part to play and all three must work together to ensure the success of the preceptorship experience (Hegenbarth et al. 2015) Multiple models of preceptorship are used in facilitating clinical learning experience for student nurses; including the Paired and Clinical Teaching Associate Models (Forber et al. 2016; Gaberson \& Oermann 2010). In the Paired Preceptorship Model (PPM) a student 
is assigned a preceptor for a day or week wherein he or she "shadows" the preceptor (Luhanga et al. 2010), while with the Clinical Teaching Associate Model (CTA) the nurse supervises three to four students who have been assigned to one to two patients (Cooper \& Lemonde 2011).

It is important to contextualize empirical research. The number of days spent on the unit corresponds to the clinical hours set forth in the curriculum (approved by the Nursing Council of Jamaica). For example, a second-year medical-surgical course could require each student to spend as many as 189 hours in the clinical area to complete a 4-credit course. Graham et al. (2016) studied 106 second year students from two schools of nursing in the Jamaica and reported that participants rated the interactions with clinical staff as the greatest source of stress at the health facilities. Further, the study found some institutions were more stressful learning environments than others. Given the independence of the institutions, schools of nursing may have limited ability to effect change in the clinical learning environment, however the need for strengthening of the supervision provided was noted. Furthermore, nurses in the practice settings are faced with heavy workload due to the presence of low retention rates among hospital nurses (World Bank 2011). As in other low and middle-income countries (Lam et al 2013), this situation is projected to become significantly worse if left unaddressed.

\subsection{Theoretical underpinnings of the study}

Krok's (2013) comprehensive review and proposition examined professionals' proclivity to share knowledge based on four behavioural theories including the "Social Exchange Theory, the Social Impact Theory, the Theory of Reasoned Action and the Theory of Planned Behaviour" (Krok, 2013, p. 101). The review concluded that knowledge is shared in the presence of an expectation of a return on investment and based on the belief that the benefit of this action outweighs the costs. Krok (2013, p. 101) purports that the "decision to impart knowledge is preceded by an intention which is influenced by the attitude towards that behaviour, subjective norms and perceived behavioural control" and is more likely to occur in the presence of empathy. Additionally, factors such as the individual's knowledge, skills to implement this behaviour, environmental limitations, behavioural emphasis and habits are also cited as being associated with the employee's inclination to share knowledge [in this case registered nurses' willingness to precept students]. Finally, qualitative research conducted in the United States of America identified "expectations of support" as one of the main themes related to nurses' willingness and perceptions of precepting students (L'Ecuyer, 2019, p.15).

\subsection{Aim}

This study sought to explore registered nurses' willingness and attitude towards precepting student nurses at a teaching hospital in Jamaica.

\subsection{Research questions}

Are registered nurses willing to precept student nurses?

What factors predict registered nurses' willingness to participate in the preceptorship process?

\section{Methods}

\subsection{Study design and setting}

A descriptive, cross-sectional, correlational study design was used to survey nurses assigned to medical and surgical units of a 579-bed tertiary referral teaching hospital in Kingston, Jamaica using a 32-item newly developed tool. This internationally recognized academic institution facilitates the clinical training of multiple healthcare professionals including: nurses, physiotherapists, pharmacists, radiologists and medical practitioners and provides specialized services to meet the healthcare needs of Jamaica.

The multidisciplinary healthcare professional team employed at the institution included more than 700 full-time and part-time nurses. Registered nurses employed at the institution on a full-time basis received limited monetary rewards for precepting/ teaching student nurses as part of their job responsibilities. The process of student supervision is unstructured and varies depending on staff nurse's availability and patient census, with faculty/ clinical instructors employed by the university visiting periodically to guide undergraduate nursing students in years two to four. Students are typically assigned a maximum of two clients and 8-hour shifts (day or evening shift).

\subsection{Inclusion/ exclusion criteria}

All full-time nurses assigned to selected medical/surgical units, employed at the study institution were included in the study. Registered nurses who were on earned and maternity leave at the time of data collection were excluded from the study.

\subsection{Sampling design}

A total of 128 nurses were assigned to the adult medical/ surgical units. Using Raosoft sample size calculator, a margin of error of 5\%, confidence interval of $95 \%$ and a distribution of $50 \%$ a recommended sample size of 97 nurses was determined.

\subsection{Data collection procedure}

The researcher was introduced to the nursing staff by the nurse manager and collected data over a 4-week period. Potential participants were provided with a letter which explained the study and described the clinical teaching associate (CTA) and paired preceptorship (PP) models of preceptorship. Following written informed consent, nurses placed completed questionnaires in sealed envelopes. These were then placed in a locked box provided in a secured office on the unit.

\subsection{Data collection instrument}

The instrument development was guided by Krok (2013, p.105) proposition regarding the willingness to share knowledge among professionals. Further modifications were made after consultation with stakeholders including nurse administrators and senior faculty at the study 
hospital and a review of the literature (Udlis, 2008). The 32-item, Attitude Towards Preceptorship (ATP) self-administered questionnaire took approximately 15 minutes to complete. Section A included 7 items related to the demographic characteristics of participants while sections B and C comprised 25 items which examined the perceived benefits to precepting student nurses [Questions 8-15 (7 items plus 1 open ended)], willingness to precept students [Questions 16-18 (3 items)], perceptions of nurses towards students and their self-efficacy [Questions 19-26 (8 items)], and normative beliefs regarding clinical environment [questions 27-31 (5 items)]. Questions 8 - 14 which assessed perceived benefits were ordinal and scored on a five-point Likert scale from minimal (1) to maximal (5). For Questions 16 - 31 options ranged from Strongly Disagree (1) to Strongly Agree (5). An additional open-ended question allowed nurses to provide comments relating to benefits of preceptorship and possible recommendations for successful preceptorship.

\subsection{Validity and reliability}

The internal consistency of the tool was measured using Cronbach's Alpha Reliability Coefficient for Likert-Type Scales. Twelve nurses from another hospital participated in the pretesting of the tool. A coefficient of 0.84 was obtained for questions related to perceived benefits of precepting. Subscales (3) in Section C had coefficient results ranging from 0.75 to 0.84 . Cronbach alpha coefficient values greater than or equal to 0.7 were acceptable for developing tools (Polit \& Beck 2013). The face validity and refinement of the tool was determined by pretesting it among four faculty members and 10 registered nurses.

\subsection{Data analyses}

Data were analysed using SPSS version 17 (SPSS Inc., Chicago, IL, USA). The responses on the 5-point Likert scale were subjected to descriptive and inferential statistical analyses. Pearson's correlation coefficient was used to examine relationships among demographic and professional characteristics and factors predictive of the nurse's willingness and attitude towards precepting students. Items assigned to the constructs of the model were subjected to exploratory factor analysis and an eigenvalue greater than 1.0 and Variable Inflation Factor of less than 2 were accepted (values above 0.5). The exploratory factor analysis yielded five components (Professional Development; Personal Satisfaction; Self-efficacy; Attitude and Empathy Towards students; and Normative Beliefs Regarding Clinical Environment). Financial Reward and Conference Discount which along with significant demographic variables were entered in a logistic regression model to determine factors predictive of registered nurse's willingness to precept students.

\subsection{Ethical considerations}

Ethical approval was obtained from the University of the West Indies, Faculty of Medical Sciences/ University Hospital of the West Indies (FMS/ UHWI) Ethics Committee and permission was granted from the hospital administration. No names were required on the questionnaire and data were kept confidential and stored in a locked cupboard and secured computer.

The benefits of the study included an opportunity to be trained as a certified preceptor (at no cost to participant). Therefore, despite the noted required sample size, all eligible registered nurses assigned to the unit were invited to participate in the study.

\section{Results}

The study achieved a response rate of $78.4 \%$ (76/97). Just over a half of the participants $(52.6 \%$; $n=40)$ were assigned to the surgical units and the remainder $47.4 \%(n=36)$ were assigned to the medical units. Participants were predominantly female $(94.7 \% ; n=72)$, trained at the baccalaureate level $(97.3 \% ; n=72)$ and $41.9 \%(n=31)$ were 26-30 years of age (Table 1). Most of the respondents had worked in the current area for fewer than five years $(90.8 \% ; \mathrm{n}=69)$ and only $10 \%$ were trained preceptors.

Table 1: Demographic Profile of Respondents

\begin{tabular}{|c|c|c|}
\hline Demographics & Frequency (n) & Percentage (\%) \\
\hline \multicolumn{3}{|l|}{ Gender } \\
\hline Male & 4 & 5.3 \\
\hline Female & 72 & 94.7 \\
\hline \multicolumn{3}{|l|}{ Age Group } \\
\hline $20-25$ & 24 & 32.4 \\
\hline 26-30 & 31 & 41.9 \\
\hline $31 \mathrm{yrs}$ or older & 19 & 25.7 \\
\hline \multicolumn{3}{|l|}{ Unit } \\
\hline Medical & 36 & 47.4 \\
\hline Surgical & 40 & 52.6 \\
\hline \multicolumn{3}{|l|}{ Length on Unit } \\
\hline 5 years or less & 69 & 90.8 \\
\hline 6 or more years & 7 & 9.2 \\
\hline \multicolumn{3}{|l|}{ Educational Level } \\
\hline Baccalaureate & 72 & 97.3 \\
\hline Graduate & 2 & 2.7 \\
\hline \multicolumn{3}{|c|}{ Years Trained as a RN } \\
\hline $0-2$ years & 4 & 5.4 \\
\hline 3-5 years & 53 & 71.6 \\
\hline 6 or more years & 17 & 23.0 \\
\hline \multicolumn{3}{|c|}{ Previous training in preceptorship } \\
\hline Yes & 8 & 10.9 \\
\hline No & 65 & 89.1 \\
\hline
\end{tabular}




\subsection{Nurses self-efficacy and attitude towards student nurses and the clinical learning environment}

Almost all study participants felt they had good communication skills (92.1\%) and were confident about their clinical competencies (92.1\%) [Table 2]. Participants viewed themselves as being good role models for students (89.4\%) and believed they had a professional responsibility to offer guidance $(89.5 \%)$.

Almost two-thirds of participants (61\%) reportedly enjoyed working with students and $97.4 \%(\mathrm{n}=74)$ felt their actions could positively influence the students' clinical learning experience. Participants $(90.8 \%)$ empathized with students as they recalled their time of undergraduate training. Only $47 \%$ of respondents viewed the faculty-based preceptorship model (nursing faculty supervising students) as a suitable preceptorship model.

\subsection{Nurses' normative beliefs about preceptorship and existing support in the clinical environment}

Most participants felt it was their responsibility to supervise student nurses (76\%; $\mathrm{n}=57)$, and claimed their colleagues at the institution provided a positive learning environment for students $(78.9 \% ; n=60)$ [Table 2]. The participants claimed nursing colleagues believed providing guidance to students was a professional responsibility $(89.5 \%)$ and were supportive of students' clinical experiences (62.7\%).

Table 2: Nurses' Self-Efficacy and Attitude Towards Student Nurses and the Clinical Learning Environment

\begin{tabular}{|c|c|c|c|}
\hline Items & Statements & $\begin{array}{l}\text { Agree } \\
\mathrm{n}(\%)\end{array}$ & Mean (SD) \\
\hline \multicolumn{4}{|c|}{ Self-efficacy } \\
\hline Item-1 & I have good communication skills & $70(92.1)$ & $4.46+0.64$ \\
\hline Item-2 & I feel confident about my clinical competences & $70(92.1)$ & $4.36+0.63$ \\
\hline Item-3 & I feel I have a professional responsibility to guide students & $68(89.5)$ & $4.29+0.65$ \\
\hline Item-4 & I think I am a good role model for students & $67(89.4)$ & $4.32+0.66$ \\
\hline \multicolumn{4}{|c|}{ Attitude and empathy towards students } \\
\hline Item-1 & I enjoy working with students & $46(63.9)$ & $3.86+0.86$ \\
\hline Item-2 & I empathize with students as I recall my days as a student & $69(90.8)$ & $4.46+0.74$ \\
\hline Item-3 & I know my actions can influence the clinical learning experience of the students & $74(97.4)$ & $4.57+0.55$ \\
\hline \multicolumn{4}{|c|}{ Normative beliefs regarding clinical environment } \\
\hline Item-1 & In general, my colleagues are of the view that nurses have a professional responsibility to guide students & $57(76.0)$ & $3.96+0.74$ \\
\hline Item-2 & My colleagues are supportive of students' clinical learning experiences & $47(62.7)$ & $3.76+0.75$ \\
\hline Item-3 & My institution provides a positive learning environment for students & $60(78.9)$ & $4.01+0.87$ \\
\hline Item-4 & $\begin{array}{l}\text { In my view the current preceptorship model where faculty is responsible for clinical supervision of students is } \\
\text { best }\end{array}$ & $36(47.4)$ & $3.47+1.09$ \\
\hline Item-5 & Currently the communication between the university and hospital is satisfactory & $27(35.5)$ & $3.16+0.94$ \\
\hline
\end{tabular}

\subsection{Perceived benefits of precepting student nurses}

Personal satisfaction was rated the most beneficial by registered nurses studied $(70.3 \% ; n=52)$. Continued education credits, $69 \%$ ( $\mathrm{n}=$ $49)$ and preceptorship training $66.5 \%(\mathrm{n}=50)$ were also rated as highly beneficial by most of the participants (Table 3$)$. Less than half of the participants rated financial rewards $(45.7 \%)$, discounted nursing research conferences $(45.5 \%)$, discounted fees for membership in the local nursing Honours Society (28.8\%), or recommendation for membership (33\%), as being highly beneficial.

Table 3: Nurses' Perception About the Maximum Benefits of Precepting Student Nurses

\begin{tabular}{|c|c|c|}
\hline Perceived Benefits & $\mathrm{n}(\%)$ & Mean (SD) \\
\hline \multicolumn{3}{|l|}{ Professional Development and Personal Satisfaction } \\
\hline -Continued education credits & $49(69.0)$ & $3.90+1.00$ \\
\hline -Preceptorship training & $50(68.5)$ & $3.93+1.10$ \\
\hline -Personal Satisfaction & $52(70.3)$ & $3.89+1.04$ \\
\hline \multicolumn{3}{|l|}{ Financial Reward and Conference Discount } \\
\hline -Financial Reward & $32(45.7)$ & $3.10+1.52$ \\
\hline -Discount at the annual Nursing Research Conference & $24(42.5)$ & $2.77+1.25$ \\
\hline -Recommendation for membership in the local Nursing Honour Society & $24(32.9)$ & $2.93+1.33$ \\
\hline -Discounted membership fees for the local Nursing Honour Society & $21(28.8)$ & $2.77+1.31$ \\
\hline
\end{tabular}

Only four participants provided additional comment on precepting students. A summary of open-ended responses highlighted the importance of precepting students, weaknesses in the faculty-based model and students' responsibilities in the preceptorship dyad were noted. Participants felt, preceptors played an important role in precepting students, helping to optimize their confidence and enhancing clinical experiences. Participants suggested "scheduled meetings to improve the process of clinical supervision". Respondents felt there was a need for more trained preceptors in the clinical areas and expressed concern about the inadequacy of the length of time faculty-based preceptors spent with each student, particularly on days when staff was busy, and the unit was short staffed". Finally, it was suggested that "...students needed to show greater interest in their learning experience."

\subsection{Nurses' willingness to precept students}

Most participants (86.9\%) indicated they were willing to precept student nurses (Table 4). The paired preceptorship model appeared to be favoured by the participants as $86.8 \%(\mathrm{n}=66)$ indicated they were willing to participate in this method ( 1 nurse: 1 student nurse) while fewer $60.6 \%(n=46)$, were willing to participate in the clinical teaching associate model [1 nurse: 4-6 student nurses]. 
Table 4: Registered Nurses' Willingness to Precept Nursing Student and to Participate in Selected Models of Preceptorship

\begin{tabular}{lll}
\hline Question & Willingness Statements & $\begin{array}{l}\text { Agree } \\
\mathrm{n}(\%)\end{array}$ \\
\hline I would be willing to precept students: & Overall & \\
Item-1 & Using the paired preceptorship model (1student to 1 nurse) & 66 (86.9) \\
Item-2 & Using the clinical teaching associate model (nurse assigned 4-6 students) & $46(60.6)$ \\
Item-3 &
\end{tabular}

\subsection{Factors predictive of registered nurses' willingness to precept students}

Spearman's correlation analysis was performed to assist in the selection of predictor variables (demographics and attributes/subscales of willingness) to be included in a logistic regression model predictive of the participant's willingness to participate in the preceptorship process model (Tables 5 and 6). Based on the significance levels, the demographic variable years trained as a RN was included in the model (Table 5). Components generated by the factor analysis: perceived benefits, attitude and empathy, self-efficacy and normative beliefs regarding clinical environment were also included [Table 7]. The models reviewed appeared to be most explanatory for the paired preceptorship model ( $\mathrm{R}^{2}$ range between 0.490 and $\left.0 \cdot 875\right)$.

Table 5: The Correlation between Nurses' Demographic Characteristics and Willingness to Precept Students

\begin{tabular}{|c|c|c|c|c|c|c|c|}
\hline \multirow[t]{2}{*}{ Categories } & \multirow[t]{2}{*}{$\mathrm{n}$} & \multicolumn{2}{|c|}{ Willingness (Overall) } & \multicolumn{2}{|c|}{ PP Model } & \multicolumn{2}{|c|}{ CTA Model } \\
\hline & & $\mathrm{r}$ & $\mathrm{p}$ & $\mathrm{r}$ & $\mathrm{p}$ & $\mathrm{r}$ & $\mathrm{p}$ \\
\hline Gender & 76 & -0.092 & 0.431 & -0.092 & 0.431 & -0.190 & 0.100 \\
\hline Age & 74 & 0.181 & 0.124 & 0.127 & 0.283 & 0.185 & 0.115 \\
\hline Unit & 76 & 0.021 & 0.860 & -0.213 & 0.064 & -0.119 & 0.305 \\
\hline Length of time on Unit & 76 & 0.124 & 0.286 & 0.124 & 0.286 & -0.114 & 0.328 \\
\hline Education level & 74 & 0.066 & 0.577 & 0.066 & 0.577 & -0.032 & 0.786 \\
\hline Years trained as a $\mathrm{RN}$ & 74 & 0.156 & 0.184 & 0.156 & 0.184 & 0.346 & $0.003^{*}$ \\
\hline
\end{tabular}

$* * \mathrm{p}<0.05$.

Table 6: The Correlation between Attitude Towards Preceptorship Subscales and Willingness to Precept Nursing Students

\begin{tabular}{|c|c|c|c|c|c|c|c|}
\hline \multirow[t]{2}{*}{ Subscales } & \multirow[t]{2}{*}{$\mathrm{n}$} & \multicolumn{2}{|c|}{ Willingness (Overall) } & \multicolumn{2}{|c|}{ PP Model } & \multicolumn{2}{|c|}{ CTA Model } \\
\hline & & $\mathrm{r}$ & $\mathrm{p}$ & $\mathrm{r}$ & $\mathrm{p}$ & $\mathrm{r}$ & $\mathrm{p}$ \\
\hline Perceived Benefits & 65 & -0.038 & $0.013 *$ & 0.306 & $0.013^{*}$ & 0.226 & 0.070 \\
\hline Attitude and empathy & 72 & 0.213 & 0.073 & 0.172 & 0.149 & 0.320 & $0.006^{*}$ \\
\hline Self-efficacy & 75 & 0.328 & $0.004 *$ & 0.409 & $0.001 *$ & 0.391 & $0.001 *$ \\
\hline $\mathrm{NB}-\mathrm{CLE}^{+}$ & 74 & 0.358 & $0.002 *$ & 0.253 & $0.030 *$ & 0.142 & 0.228 \\
\hline
\end{tabular}

${ }^{+}$Normative beliefs regarding clinical learning environment; ${ }^{*} \mathrm{p}<0.05$.

Table 7: Factors Predictive of Registered Nurses' Willingness to Precept Students

\begin{tabular}{|c|c|c|c|c|c|c|c|c|c|}
\hline \multirow[t]{2}{*}{ Factors } & \multicolumn{3}{|c|}{ Willingness (Overall) $(n=63)$} & \multicolumn{2}{|c|}{ PP Model $(n=63)$} & \multicolumn{4}{|c|}{ CTA Model $(\mathrm{n}=70)$} \\
\hline & $\mathrm{B}$ & SE & $\mathrm{e}^{\mathrm{B}}$ & $\mathrm{B}$ & SE & $\mathrm{e}^{\mathrm{B}}$ & $\mathrm{B}$ & SE & $\mathrm{e}^{\mathrm{B}}$ \\
\hline Years trained as a RN & & & & & & & 0.087 & 0.172 & 1.091 \\
\hline Perceived Benefits & -0.038 & 0.077 & 0.963 & 1.108 & 0.567 & 3.028 & & & \\
\hline Attitude and empathy & & & & & & & 0.208 & 0.184 & 1.231 \\
\hline Self-efficacy & 0.423 & 0.243 & 1.527 & 2.998 & 1.486 & $20.043^{*}$ & 0.509 & 0.165 & $1.663^{*}$ \\
\hline $\mathrm{NB}-\mathrm{CLE}$ & 0.686 & 0.253 & $1.985^{*}$ & 0.009 & 0.337 & 1.009 & & & \\
\hline Cox \& Snell $\mathrm{R}^{2}$ & & 0.260 & & & 0.490 & & & 0.235 & \\
\hline Nagelkerke $\mathrm{R}^{2}$ & & 0.465 & & & 0.875 & & & 0.319 & \\
\hline$X^{2}$ & & 18.986 & & & 42.385 & & & 18.777 & \\
\hline df & & 3 & & & 3 & & & 3 & \\
\hline
\end{tabular}

${ }^{+}$Normative beliefs regarding clinical learning environment; ${ }^{*} \mathrm{p}<0.05$.

\section{Discussion}

Registered nurses had positive attitudes and outlooks towards preceptorship of student nurses in the Jamaican practice setting. They felt that they possessed the necessary attributes for successful preceptorship. Further, most study participants had a positive attitude towards preceptorship and high levels of empathy towards the students. Positive attitudes and emotions were facilitators of the preceptorship relationship (Rebholz \& Baumgartner 2015). Majority of the nurses studied were desirous of being trained as preceptors (a benefit offered in this study). The respondents appeared to embrace their responsibility to create an environment suitable for knowledge and skill acquisition with participants predominantly agreeing it was their professional responsibility to supervise student nurses. This was well aligned with the International Council of Nurses Code of Ethics (2000).

Nurse preceptors in Palm Beach Florida, USA considered having their efforts acknowledged and adequate communication with faculty as more important than additional pay (Raines 2012).

In the current study, the nurses suggested regularly scheduled meetings with faculty and concessions to professional organizations membership and activities were strong facilitators of their willingness to precept. Similar sentiments have been expressed among undergraduate nurse preceptors in the US who wanted more than 'just time with students' as they craved interaction with faculty such as an opportunity to talk with faculty about the students' activities in the clinical setting (Liu et al. 2019; Raines 2012, p.78). This type of interaction is likely to advance the preceptorship confidence and role ( $\mathrm{O}^{\prime}$ Brien, 2014) and could herald a less stressful work environment for the preceptor (Liu et al. 2010). Possible negative outcomes were also associated with preceptorship when performance reviews failed to recognize the work of the preceptor (Raines 2012; Donely et al. 2014). 
Nursing and other health professions have consistently identified communication and interpersonal relationships as qualities of effective preceptors (Myrick et al. 2010; Omer et al. 2016; Young et al. 2014; Smoker 2018). In this study, nearly all participants felt they possessed effective communication skills which they deemed essential to the preceptorship process. Rebholz and Baumgartner's (2015) qualitative study concluded that preceptors' mentoring and instructions were reflective of their emotional memories of their own clinical learning experience. Feelings of empathy towards the student nurses were dominant among the nurses studied and reflected positive feelings towards the profession and high levels of professionalism.

Typically, preceptors are the role models and resource persons who are immediately available to students as they engage in their practice and facilitate a climate conducive to learning and knowledge transfer (Liu et al. 2010; Myrick et al. 2010; Omer et al. 2016; Smoker 2018). Participants in the current study also described themselves as good role models; this was significant since lower rates of retention in the profession were associated with preceptors being judged as negative role models or lacking specific knowledge (Stagg et al. 2012).

Correlational analysis revealed nurses' age and level of self-efficacy were associated with increased likelihood of being willing to precept. However, like O'Brien (2014) both variables lost their significance post regression analysis. O'Brien (2014) contended there was no relationship between age and functionality as preceptors; instead researchers cited access to training, workload and communication with faculty as predictors of willingness to precept. Comparable to the work of Liu et al. (2010) nurses studied cited patient load, inadequate staffing and time constraints as barriers to precepting. These challenges are likely to exist in fast paced environments, with heavily dependent patients and could undermine the benefits of preceptorship (Donely et al. 2014). This underscores the need for adequate collaboration and leadership in schools of nursing and practice settings.

The relationship between the school and the hospital was cited as a weakness in the preceptorship process and which can be strengthened by creating partnerships between nursing programs and clinical staff (Shepard \& Allen 2014). The perceptions of the nurses studied are consistent with current evidence which recognize the role of the clinical institution in nursing education as an important factor which promotes preceptorship (Raines 2012; Schaubhut \& Gentry 2010; Shepard \& Allen 2014). The study participants believed their colleagues at the institution provided a positive learning environment for students. This normative belief regarding clinical learning environment was correlated with participants' willingness. It is similar to the perceptions of preceptors in Saudi Arabia who primarily viewed their roles as important; particularly in reducing errors among students (Omer et al. 2015). The participants also viewed the paired preceptorship model as more favourable than the clinical teaching associate model and less than a half of the nurses viewed the faculty-based preceptorship model (nurse educators supervising students) as a suitable preceptorship model. Omer et al.'s (2013) study of nursing students in Saudi Arabia who also favoured the paired preceptorship model in mentoring rather than the models which required greater independence and self-directed learning such as the clinical teaching associate or faculty-based model. These findings also support the work of Lui, 2010 and 2019 which highlight the importance of support and increased communication among stakeholders.

The need for more trained preceptors in the clinical areas and the limited time faculty-based preceptors spent with students in the clinical area were highlighted as weaknesses in the faculty-based model. Like the current study, Raines (2012) and L'Ecuyer (2019), describe concerns among preceptors regarding the student's level of preparedness, interest, and willingness to integrate in the activities of the unit; underscoring the complexity of the preceptorship relationship across the United States. The preceptor's proclivity to require the students to display high levels of commitment are thought to be reminiscent of the nurses' own student experience (Raines 2012).

\subsection{Preceptor recruitment and retention}

Opportunities to participate in professional developmental programs, such as the preceptor training programs, are well-known avenues for hospital administrators and nursing schools to recognize the contributions of nurse preceptors and to increase job satisfaction (Muir et al. 2013; Shinners et al. 2013). Participants suggested that the preceptorship process offered them an opportunity to contribute to the development of the profession. They viewed personal satisfaction and acquiring continued education as the most important potential benefits of precepting students; as was noted by Shinners et al. (2013). Nurse preceptor satisfaction is a key factor in the retention of nurses who were willing and qualified to precept in acute care settings in the US (Shinners et al. 2013; Staykova et al. 2013). DeWolfe et al. (2010), reported nurse preceptors affiliated with a Canadian university also suggested benefits of being a preceptor included remaining current and stimulated in their profession and derived personal satisfaction from helping students to apply knowledge in the practice setting. This is consistent with the current study, as participants claimed receiving feedback from students about their experience was beneficial and gave the preceptor great satisfaction.

\subsection{Limitations of the study}

This study population was limited to a single teaching quasi government hospital and participants were selected using a convenience sampling technique. Study results may differ in a lower resource hospital setting. Further research is warranted to explore nurse's attitude after being provided formal preceptor training.

\section{Conclusion}

Nurses studied appeared to be willing to precept students and felt preceptorship was a significant process in developing the profession of nursing; ensuring well trained professionals. The perceptions of Jamaican nurses regarding the most important characteristics of good preceptors included interpersonal relationships and academic competences. Remuneration, although important was not the most significant facilitator of preceptorship as factors such as self-efficacy, training and emotions appeared to be more impactful on the preceptorship dyad. Improved faculty communication and partnership to ensure a harmonious preceptorship process is also recommended. Krok's 2012 framework appeared to be an effective guide for the achieving the aim of this study. The findings suggest that self-efficacy, desire for professional development and personal satisfaction best explained the nurses' willingness to participate in the paired preceptorship model. 


\section{Acknowledgement}

We are grateful to Donnette Wright-Myrie (The University of the West Indies, Mona) for her comments on the early manuscript draft.

\section{References}

[1] Andreas, A. (2016). Knowledge and Attitude towards Nursing Clinical Preceptorship among Nurse Educators Working in Teaching Institutions in Addis Ababa, Ethiopia (Doctoral dissertation, AAU, 2015.).

[2] Barker, E. R., \& Pittman, O. (2010). Becoming a super preceptor: a practical guide to preceptorship in today's clinical climate. Journal of the American Academy of Nurse Practitioners, 22(3), 144-149. https://doi.org/10.1111/j.1745-7599.2009.00487.x.

[3] Bott, G., Mohide, E. A., \& Lawlor, Y. (2011). A clinical teaching technique for nurse preceptors: the five minute preceptor. Journal of Professional Nursing, 27(1), 35-42. https://doi.org/10.1016/j.profnurs.2010.09.009.

[4] Carlson, E., Pilhammar, E., \& Wann-Hansson, C. (2010). "This is nursing": Nursing roles as mediated by precepting nurses during clinical practice. Nurse Education Today, 30(8), 763-767. https://doi.org/10.1016/j.nedt.2010.01.020.

[5] Christine, O. M., Cunliffe, E., Surajah, H., \& Breeze, J. (2000). Preceptorship in practice. Nursing Standard, 14(28), 45-49. https://doi.org/10.7748/ns2000.03.14.28.45.c2801.

[6] Cooper Brathwaite, A., \& Lemonde, M. (2011). Team preceptorship model: A solution for students' clinical experience. International Scholarly Research Notices Nursing. https://doi.org/10.5402/2011/530357.

[7] DeWolfe, J. A., Perkin, C. A., Harrison, M. B., Laschinger, S., Oakley, P., Peterson, J. A., \& Seaton, F. (2010). Strategies to prepare and support preceptors and students for preceptorship: A systematic review. Nurse Educator, 35(3), 98-100. https://doi.org/10.1097/NNE.0b013e3181d95014.

[8] Donley, R., Flaherty, M., Sarsfield, E., Burkhard, A., O’Brien, S., \& Anderson, K. (2014). Graduate clinical nurse preceptors: implications for improved intra-professional collaboration. OJIN: The Online Journal of Issues in Nursing, 19(3).

[9] Duteau, J. (2012). Making a difference: The value of preceptorship programs in nursing education. The Journal of Continuing Education in Nursing, 43(1), 37-43. https://doi.org/10.3928/00220124-20110615-01.

[10] Evans, L., Costello, M., Greenberg, H., \& Nicholas, P. K. (2013). The attitudes and experiences of registered nurses who teach and mentor nursing students in the acute care setting. Journal of Nursing Education and Practice, 3(2), 67. https://doi.org/10.5430/jnep.v3n2p67.

[11] Harrison-White, K., \& Simons, J. (2013). Preceptorship: ensuring the best possible start for new nurses: Karen Harrison-White and Joan Simons assess the views of preceptors and preceptees in a practice-based project. Nursing children and young people, $25(1)$, 24-27. https://doi.org/10.7748/ncyp2013.02.25.1.24.s9536.

[12] Happell, B. (2009). A model of preceptorship in nursing: reflecting the complex functions of the role. Nursing Elducation Perspectives, 30(6), 372376.

[13] International Council of Nurses [ICN] (2000). The ICN Code of Ethics for Nurses. Geneva, Switzerland. Author. Retrieved August 29, 2016, from https://www.nsf.no/Content/113948/icncode.pdf

[14] James, A., \& Chapman, Y. (2010). Preceptors and patients-the power of two: nursing student experiences on their first acute clinical placement. Contemporary Nurse, 34(1), 34-47. Doi: 10.5172/conu.2009.34.1.034Krok, E. (2013). Willingness to share knowledge compared with selected social psychology theories. Contemporary Economics, 7(1), 101-109. https://doi.org/10.5172/conu.2009.34.1.034.

[15] Lam, B., Fong, P., \& Yuan, H. (2013). Nursing shortage: the facts and strategies in Macao society. OJIN: The Online Journal of Issues in Nursing, $18(1)$

[16] L'Ecuyer, K. M. (2019). Perceptions of nurse preceptors of students and new graduates with learning difficulties and their willingness to precept them in clinical practice (Part 2). Nurse education in practice, 34, 210-217. https://doi.org/10.1016/j.nepr.2018.12.004

[17] Liu, M., Chan, Y. M., Tee, S., Gu, K., Luo, M. Z., \& Wong, T. K. (2019). An iterative approach to enhance the clinical learning experience in Macao nursing education. International Journal of Nursing Sciences. https://doi.org/10.1016/j.ijnss.2019.01.005.

[18] Liu, M., Lei, Y., Mingxia, Z., \& Haobin, Y. (2010). Lived experiences of clinical preceptors: A phenomenological study. Nurse Education Today, 30(8), 804-808. https://doi.org/10.1016/j.nedt.2010.03.004.

[19] McClure, E., \& Black, L. (2013). The role of the clinical preceptor: an integrative literature review. Journal of Nursing Education, 52(6), 335-341. https://doi.org/10.3928/01484834-20130430-02.

[20] McSharry, E., \& Lathlean, J. (2017). Clinical teaching and learning within a preceptorship model in an acute care hospital in Ireland; a qualitative study. Nurse Education Today, 51, 73-80. https://doi.org/10.1016/j.nedt.2017.01.007.

[21] Muir, J., Ooms, A., Tapping, J., Marks-Maran, D., Phillips, S., \& Burke, L. (2013). Preceptors' perceptions of a preceptorship programme for newly qualified nurses. Nurse Education Today, 33(6), 633-638. https://doi.org/10.1016/j.nedt.2013.02.001.

[22] Myrick, F., Yonge, O., \& Billay, D. (2010). Preceptorship and practical wisdom: a process of engaging in authentic nursing practice. Nurse Education in Practice, 10(2), 82-87. https://doi.org/10.1016/j.nepr.2009.03.018.

[23] Omansky, G. L. (2010). Staff nurses' experiences as preceptors and mentors: an integrative review. Journal of Nursing Management, 18(6), 697703. https://doi.org/10.1111/j.1365-2834.2010.01145.x.

[24] Omer, T. A., Suliman, W. A., \& Moola, S. (2016). Roles and responsibilities of nurse preceptors: Perception of preceptors and preceptees. Nurse Education in Practice, 16(1), 54-59. https://doi.org/10.1016/j.nepr.2015.07.005.

[25] Omer, T. Y., Suliman, W. A., Thomas, L., \& Joseph, J. (2013). Perception of nursing students to two models of preceptorship in clinical training. Nurse Education in Practice, 13(3), 155-160. https://doi.org/10.1016/j.nepr.2013.02.003.

[26] Parker, F. M., Lazenby, R. B., \& Brown, J. L. (2012). Mission possible CD ROM: Instructional tool for preceptors. Nurse Education Today, 32(5), 561-564. https://doi.org/10.1016/j.nedt.2011.08.009.

[27] Raines, D. A. (2012). Nurse preceptors' views of precepting undergraduate nursing students. Nursing Education Perspectives, 33(2), 76-79. https://doi.org/10.5480/1536-5026-33.2.76.

[28] Rebholz, M., \& Baumgartner, L. M. (2015). Attributes and Qualifications of Successful Rural Nurse Preceptors: Preceptors' Perspectives. The Qualitative Report, 20(2), 93.

[29] Schaubhut, R. M., \& Gentry, J. A. (2010). Nursing preceptor workshops: Partnership and collaboration between academia and practice. The Journal of Continuing Education in Nursing, 41(4), 155-160. https://doi.org/10.3928/00220124-20100326-01.

[30] Schuelke, S., \& Barnason, S. (2017). Interventions Used by Nurse Preceptors to Develop Critical Thinking of New Graduate Nurses: A Systematic Review. Journal for Nurses in Professional Development, 33(1), E1-E7. https://doi.org/10.1097/NND.0000000000000318.

[31] Shepard, L., \& Allen, G. (2014). Building Collaborative Partnerships between Academia and Hospitals to Enhance Preceptorship Experiences. IManager's Journal on Nursing, 4(2), 1. https://doi.org/10.26634/jnur.4.2.2769.

[32] Shinners, J., Mallory, C., \& Franqueiro, T. (2013). Preceptorship today: Moving toward excellence. The Journal of Continuing Education in Nursing, 44(11), 482-483. https://doi.org/10.3928/00220124-20131025-91.

[33] Smedley, A. M. (2008). Becoming and being a preceptor: A phenomenological study. The Journal of Continuing Education in Nursing, 39(4), 185191. https://doi.org/10.3928/00220124-20080401-08.

[34] Smoker, F. E. (2018). Qualitative Study to Investigate Factors Influencing Preceptors' Role in Precepting BSN Students (Doctoral dissertation, Capella University).

[35] Stagg, P., Prideaux, D., Greenhill, J., \& Sweet, L. (2012). Are medical students influenced by preceptors in making career choices, and if so how? A systematic. Rural and Remote Health, 12(1832). 
[36] Staykova, M. P., Huson, C., \& Pennington, D. (2013). Empowering nursing preceptors to mentoring undergraduate senior students in acute care settings. Journal of Professional Nursing, 29(5), e32-e36. https://doi.org/10.1016/j.profnurs.2013.06.003.

[37] Udlis, K. A. (2008). Preceptorship in undergraduate nursing education: An integrative review. The Journal of Nursing Education, 47(1), 20-29. https://doi.org/10.3928/01484834-20080101-09.

[38] Walker, S., Dwyer, T., Moxham, L., Broadbent, M., \& Sander, T. (2013). Facilitator versus preceptor: which offers the best support to undergraduate nursing students? Nurse Education Today, 33(5), 530-535. https://doi.org/10.1016/j.nedt.2011.12.005.

[39] Young, S., Vos, S. S., Cantrell, M., \& Shaw, R. (2014). Factors associated with students' perception of preceptor excellence. American Journal of Pharmaceutical Education, 78(3), 53. https://doi.org/10.5688/ajpe78353.

[40] World Bank. Migration and remittances factbook 2011: Jamaica. http://siteresources.worldbank.org/INTPROSPECTS/Resources/3349341199807908806/Jamaica.pd. Accessed January 30, 2016 